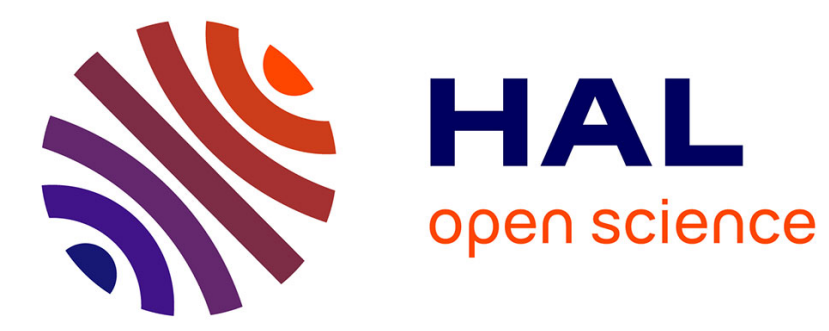

\title{
Shock wave mitigation propagating through a cavity
}

\author{
A. Marty, G. Jourdan, L. Houas, C. C. Mariani, E. Daniel, L. Biamino, D. \\ Leriche
}

\section{To cite this version:}

A. Marty, G. Jourdan, L. Houas, C. C. Mariani, E. Daniel, et al.. Shock wave mitigation propagating through a cavity. 32nd International Symposium on Shock Waves (ISSW32), Jul 2019, Singapour, Singapore. hal-02399938

\section{HAL Id: hal-02399938 \\ https://hal.science/hal-02399938}

Submitted on 9 Dec 2019

HAL is a multi-disciplinary open access archive for the deposit and dissemination of scientific research documents, whether they are published or not. The documents may come from teaching and research institutions in France or abroad, or from public or private research centers.
L'archive ouverte pluridisciplinaire HAL, est destinée au dépôt et à la diffusion de documents scientifiques de niveau recherche, publiés ou non, émanant des établissements d'enseignement et de recherche français ou étrangers, des laboratoires publics ou privés. 


\title{
Shock wave mitigation propagating through a cavity
}

\author{
A. Marty, G. Jourdan, L. Houas, C. Mariani, E. Daniel, L. Biamino \\ Aix Marseille Univ, CNRS, IUSTI, Marseille, France \\ D. Leriche \\ DGA/Techniques Navales, Avenue de la Tour Royale, 83050 Toulon Cedex, France \\ Corresponding Author's name: antoine.marty@univ-amu.fr
}

\begin{abstract}
In the present paper, the propagation of a planar shock wave through a ' $Y$ ' bifurcation duct with a trap added is both experimentally and numerically studied. Experiments were conducted in a square cross-section shock tube for three differents shock wave Mach numbers. A specific test section having a ' $Y$ ' bifurcation was installed at the end of the shock tube. Pressures were recorded at different locations of the device using piezo-electric pressure transducers. The present study focuses on the mitigation of the pressure level induced by the propagation of a shock wave in the device with the addition of trap (cavity) located along the model. With the support of numerical simulations we show that both the location and geometric aspect ratio of the trap have a significant influence on the pressure level prevailing in the duct system.
\end{abstract}

\section{Introduction}

In the research for protection from explosions, a variety of underground shelters were proposed during the previous decades as Ben-Dor et al. [1], Igra et al. [2]. An important feature in designing such protection is the knowledge of shock or blastwave propagation in ducts leading to the shelter. This knowledge is also of importance for safety precautions in mines in case of sudden explosions. The propagation of a planar shock wave through a $\mathrm{Y}$ bifurcation duct system was experimentally and numerically studied in a previous work [3]. This study showed the influence of the bifurcation on the attenuation of the end-wall reflected pressure. The present work is now focused on the influence of added traps located at different locations. Figure 1 represents the $\mathrm{Y}$ device with a trap located on the lower wall of the bottom branch. The goal is to determine if it could have any effect on the end-wall reflected pressure and consequently on the attenuation. In parallel, to support the experiments, numerical simulations were conducted using a self-made code called ECOGEN [4] based on the solution of Euler equations with a Godunov scheme. A numerical parametric study on the size and the location of the trap was conducted in order to optimize the efficiency. The location and the size of the trap is studied for three cases : two parallelepipedic cavities located respectively on the upper and the lower branch wall, and the third one located on the point of bifurcation of the device. Three different incident planar shock waves with Mach number equal to 1.12, 1.36 and 1.69 are studied for each configuration.

\section{$1.1 \quad$ Experimental set-up}

Experiments were conducted in a $80 \times 80 \mathrm{~mm}^{2}$ square cross-section shock tube for which a specific test section was designed (Figs.1 and 2). Piezo-sensitive pressure transducers were flush mounted to record information at different locations, along the shock tube wall and inside the $\mathrm{Y}$ device. The flow pattern was also analyzed from visualizations using a 


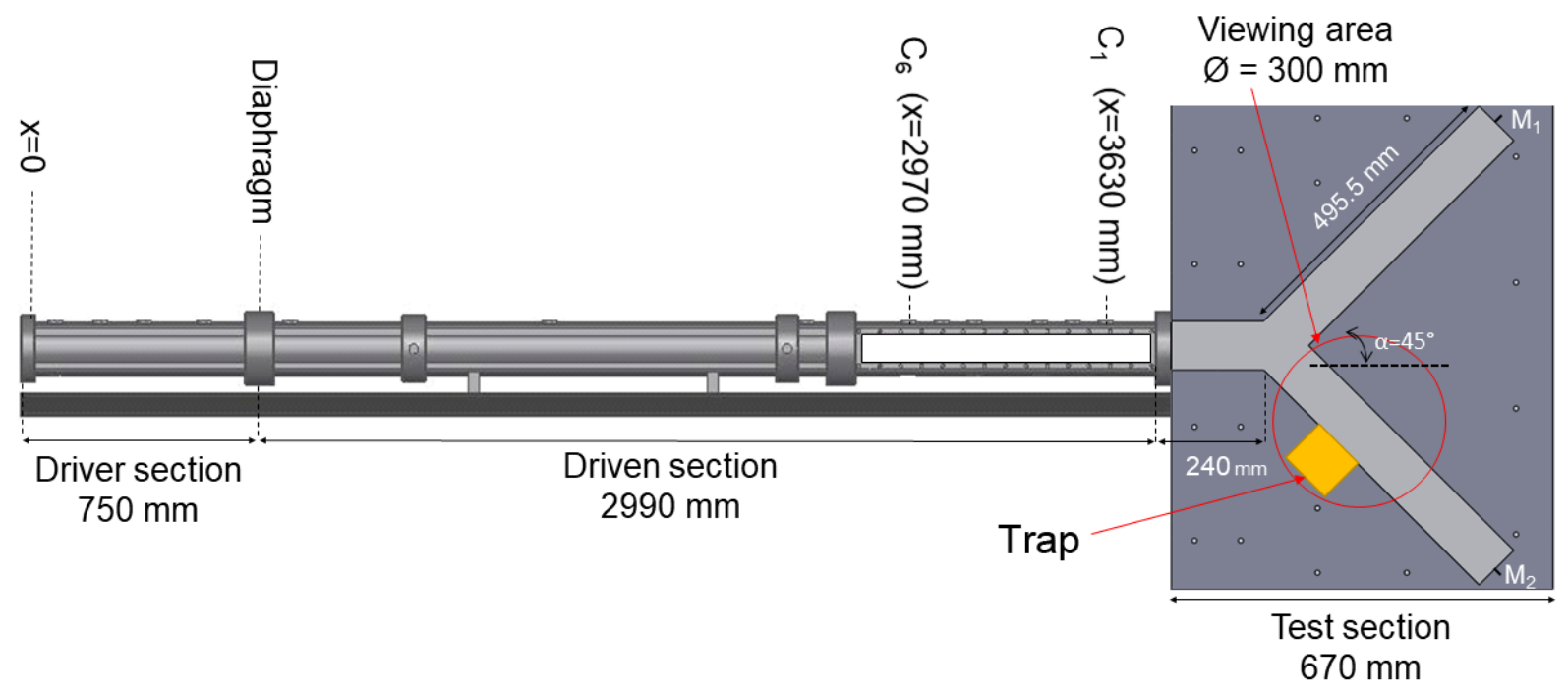

Fig.1 Scheme of the experimental setup: the T80 shock-tube, the Y-shaped test section and the pressure transducers arrangement.

high-speed schlieren system. More details of the experimental set-up are presented in our previous work conducted with the "Y"-shaped test section without trap [3].

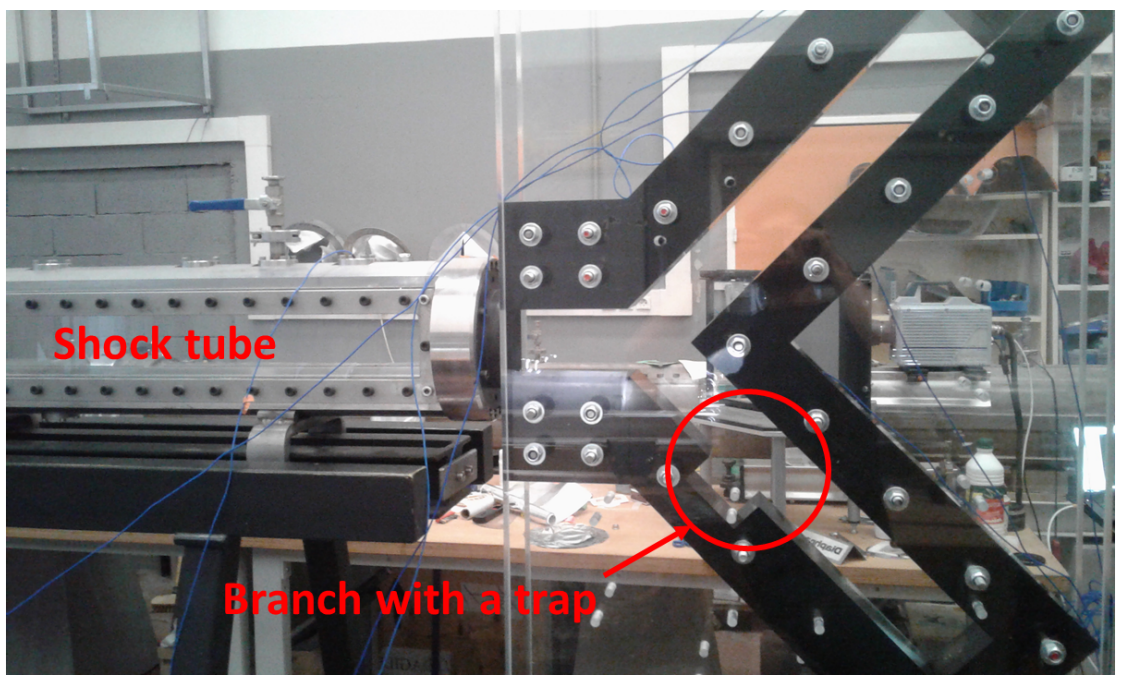

Fig.2 Photography showing the test section with the trap in the lower branch. Trap size: $80 \times 40 \mathrm{~mm}^{2}$

\subsection{Experimental highlighting}

This preliminary experimental work has enabled us to check if this kind of trap could be efficiency in the mitigation of the pressure level in the device. The cavity in the lower branch mesures $80 \mathrm{~mm}$ in length and has a depth of $40 \mathrm{~mm}$. Figure 3 represents a comparison of the reflected pressure recorded respectively at the end-wall of the branch without the trap $\left(\mathrm{M}_{1}\right.$, black line) and with the trap $\left(\mathrm{M}_{2}\right.$, red line). We clearly observe the reduction of the pressure peak when the shock wave reflected off the end-wall in the presence of a trap located on the path of the shock wave. 


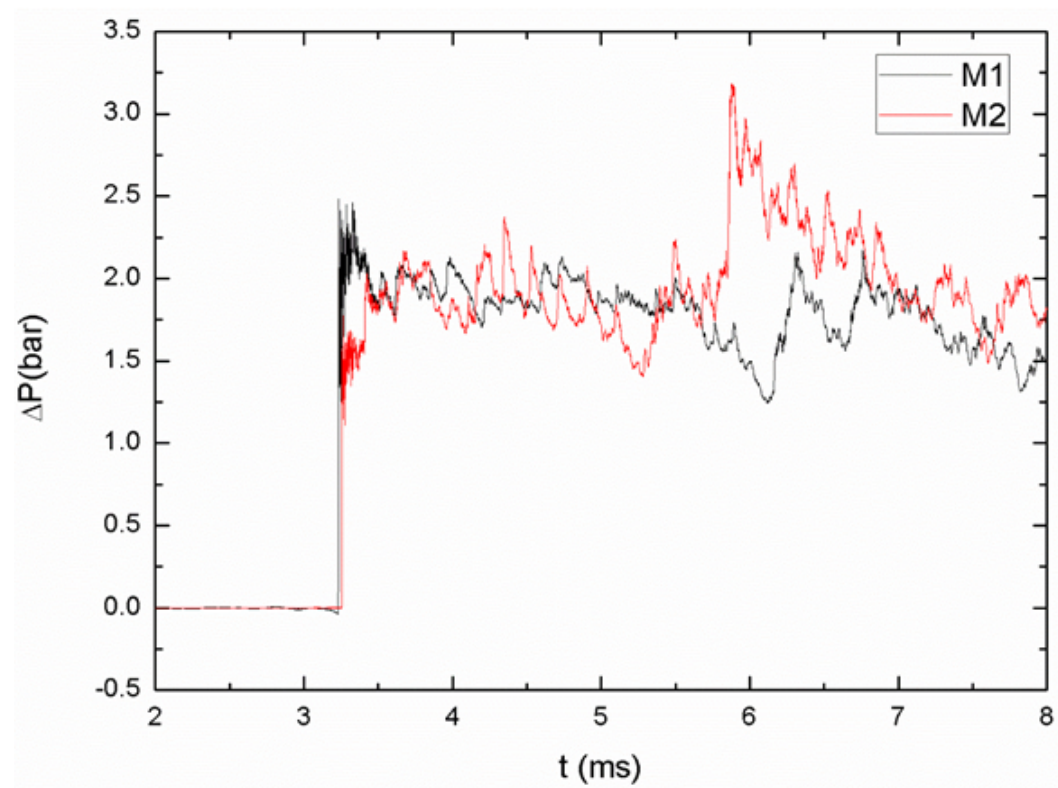

Fig.3 Comparison of the reflected pressure recorded at the end-wall, of the branch without the trap $\left(\mathrm{M}_{1}\right.$, black line) and the branch with the trap $\left(\mathrm{M}_{2}\right.$, red line). The incident shock wave Mach number is 1.36 .

Experimentally study the influence of both the location and aspect ratio of the trap requiring many technical modifications, we have subsequently conducted numerical simulations.

\subsection{Numerical validation}

Numerical sumulations were conducted using ECOGEN [4], a personal open-source code based on the solution of the Euler equations with a second-order Godunov scheme. Figure 4 presents a comparison between experimental and numerical schlieren picture (a) and pressure traces recorded at the end-wall of the device (b) induced by the propagation of a shock wave through a trap located on the lower wall. It confirms the good agreement between both approaches (less than $5 \%$ of error on the mean value). In the following, considering a trap successively located on the lower wall, the upper wall or at the point of bifurcation, a parametric study of the size and the location of the trap was numerically studied. 


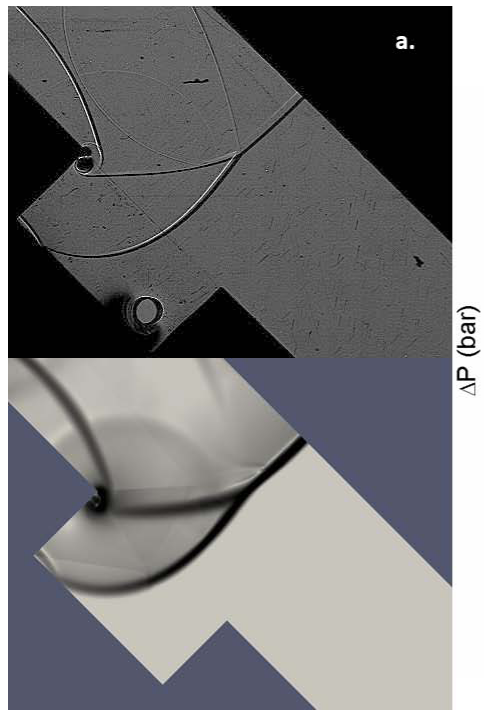

b.

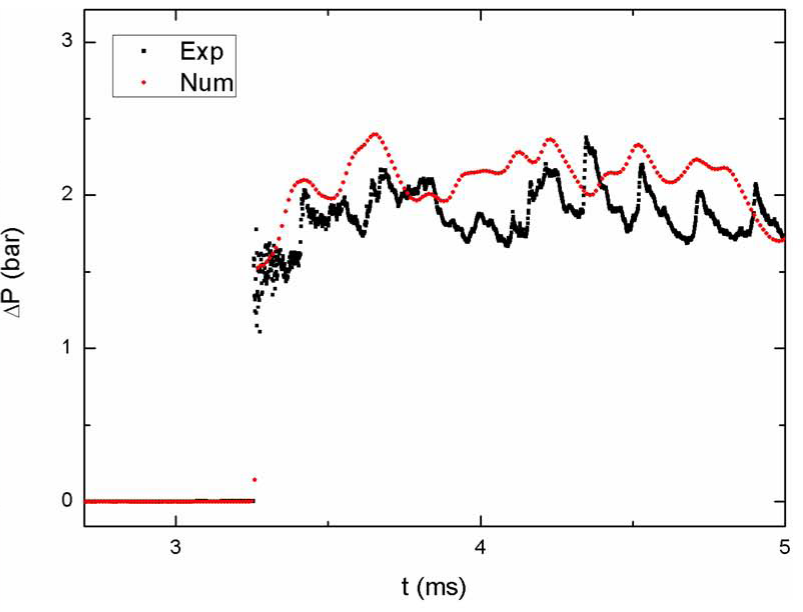

Fig.4 a. Experimental (top) and numerical (bottom) schlieren picture of a shock wave propagating through a trap located on the lower wall at same time. b. Comparison of the evolution of the pressure signal in the Y-shape for an incident shock wave Mach number of 1.36 at the end-wall ( $\mathrm{M}_{1}$, black line) and its numerical equivalents (red line).

\section{Results and discussion}

\subsection{Influence of a trap located on the upper wall}

\subsubsection{Influence of the parameter $d$}

Figure 5 shows the geometric characteristics of the trap located on the upper wall. For the influence of the location, the size of the cavity was arbitrarily set at the characteristic length of the shock tube, i.e, $\mathrm{L}=80 \mathrm{~mm}$ and $\mathrm{H}=80 \mathrm{~mm}$.

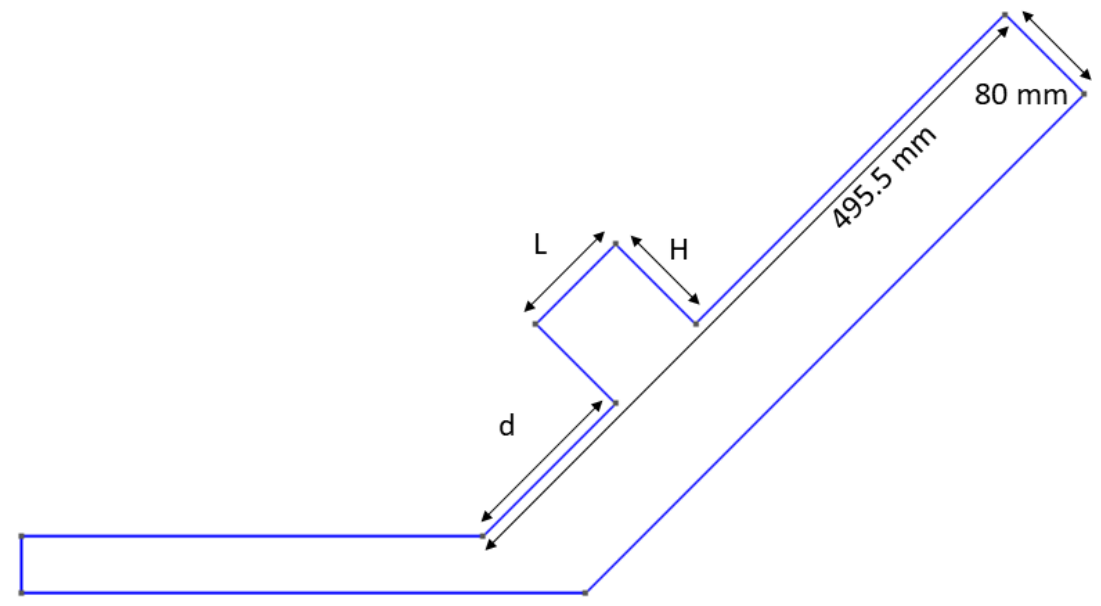

Fig.5 Geometric characteristics of the trap located on the upper wall.

For different values of $d$ ranging from 0 to $0.4 \mathrm{~m}$, we compare the reflected pressure recorded at the end-wall of the branch in the presence of the trap $\left(\mathrm{P}_{r}\right)$ with a reference pressure recorded without the trap $\left(\mathrm{P}_{\max }\right)$. Results are presented in Fig.6. 


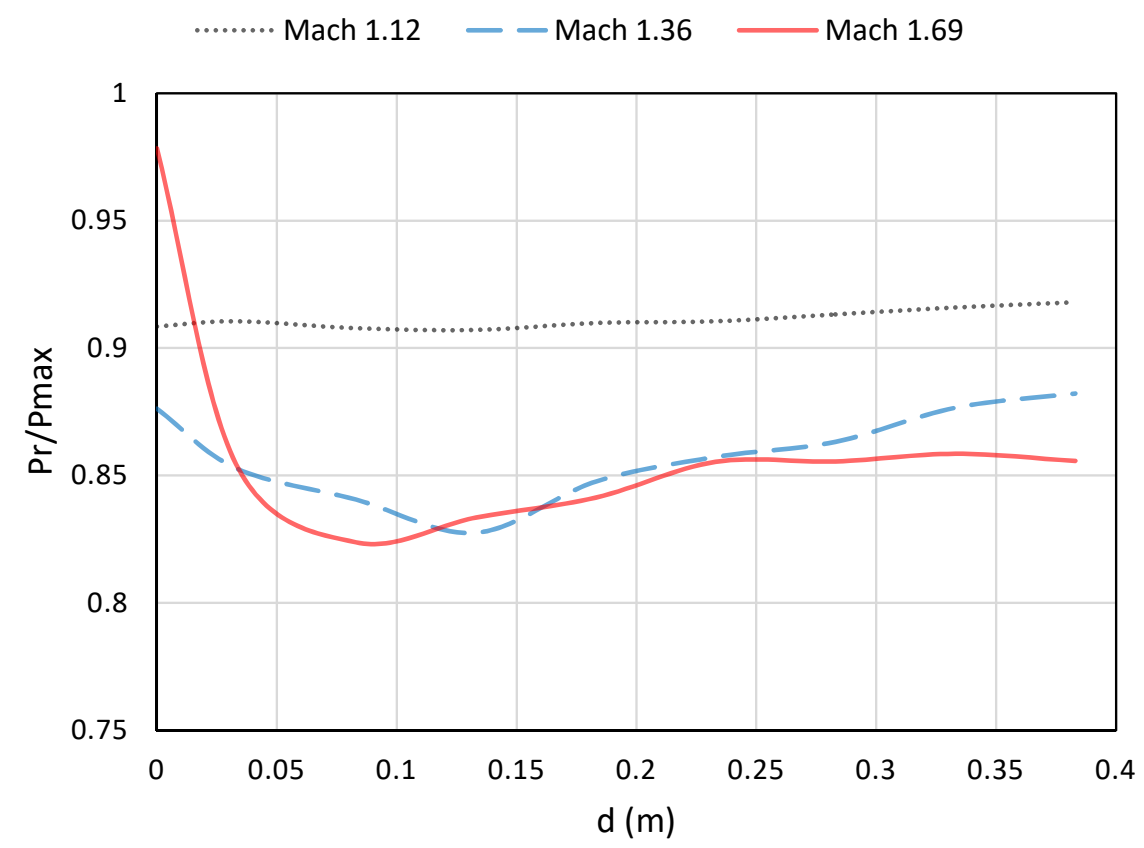

Fig.6 Evolution of the reflected pressure ratio $\mathrm{P}_{r} / \mathrm{P}_{\max }$ for different values of $d$

Figure 6 shows that the optimal location of the trap is approximatively at $\mathrm{d}=0.12 \mathrm{~m}$. The presence of a trap at this location can mitigate up to $18 \%$ the reflected pressure.

\subsubsection{Influence of the parameter $L / H$}

Now that the optimal location of the trap was identified and fixed at $d=0.12 \mathrm{~m}$, we studied the influence of the ratio $R=L / H$ making sure to keep the same cavity area set at $80 \times 80 \mathrm{~mm}^{2}$.

Table 1 Values of the parameters $L, H$ et $L / H$ studied.

\begin{tabular}{|c|c|c|}
\hline$L(\mathrm{~m})$ & $H(\mathrm{~m})$ & $R=L / H$ \\
\hline 0.32 & 0.02 & 16 \\
\hline 0.21 & 0.03 & 7 \\
\hline 0.16 & 0.04 & 4 \\
\hline 0.08 & 0.08 & 1 \\
\hline 0.053 & 0.12 & 0.444 \\
\hline 0.04 & 0.16 & 0.25 \\
\hline
\end{tabular}

Table 1 and Figure 7 present the different values of $R$ and geometric aspect ratios of the traps studied. 


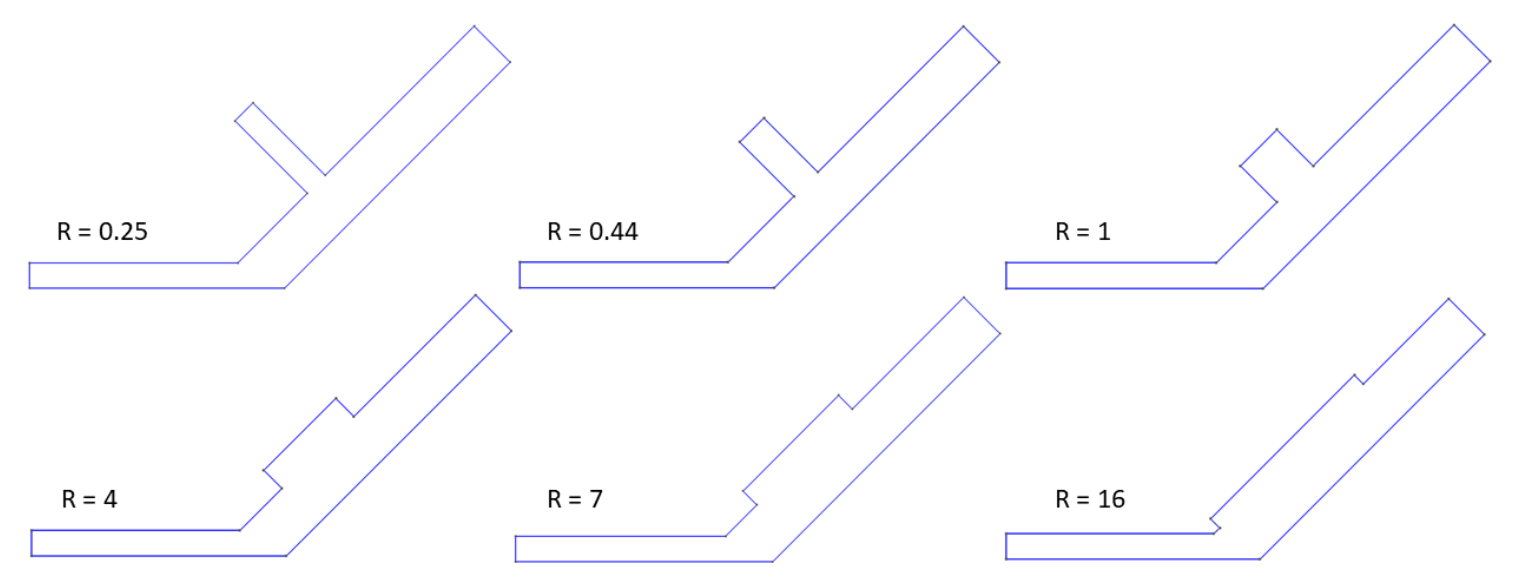

Fig.7 Geometric aspect of the trap according to different ratios $R=L / H$

Figure 8 presents the evolution of the reflected pressure ratio $\mathrm{P}_{r} / \mathrm{P}_{\max }$ for different values of $L / H$.

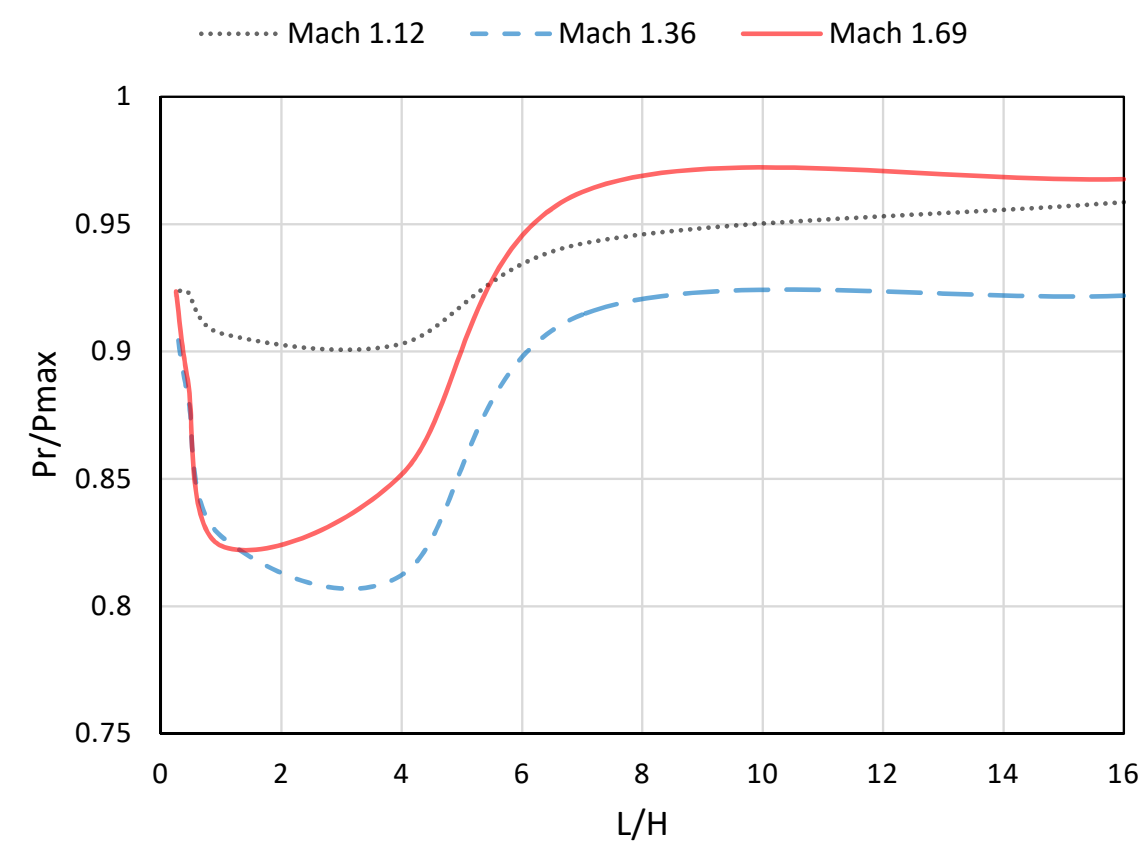

Fig.8 Evolution of the reflected pressure ratio $\mathrm{P}_{r} / \mathrm{P}_{\max }$ for different values of the parameter $L / H$

As we can see in Fig.8, the optimal ratio of $L / H$ is between 1 and 4 .

\subsection{Influence of a trap located on the lower wall}

This section presents the same parametric study considering now the effect of a trap located on the lower wall as shown in Fig.9. Only the values of the parameter $d$ have been changed for layout reasons. 


\subsubsection{Influence of the parameter $d$}

As in the previous case, both $\mathrm{L}$ and $\mathrm{H}$ are set at $80 \times 80 \mathrm{~mm}^{2}$. The parameter $d$ varies from 0.1 to $0.4 \mathrm{~m}$.

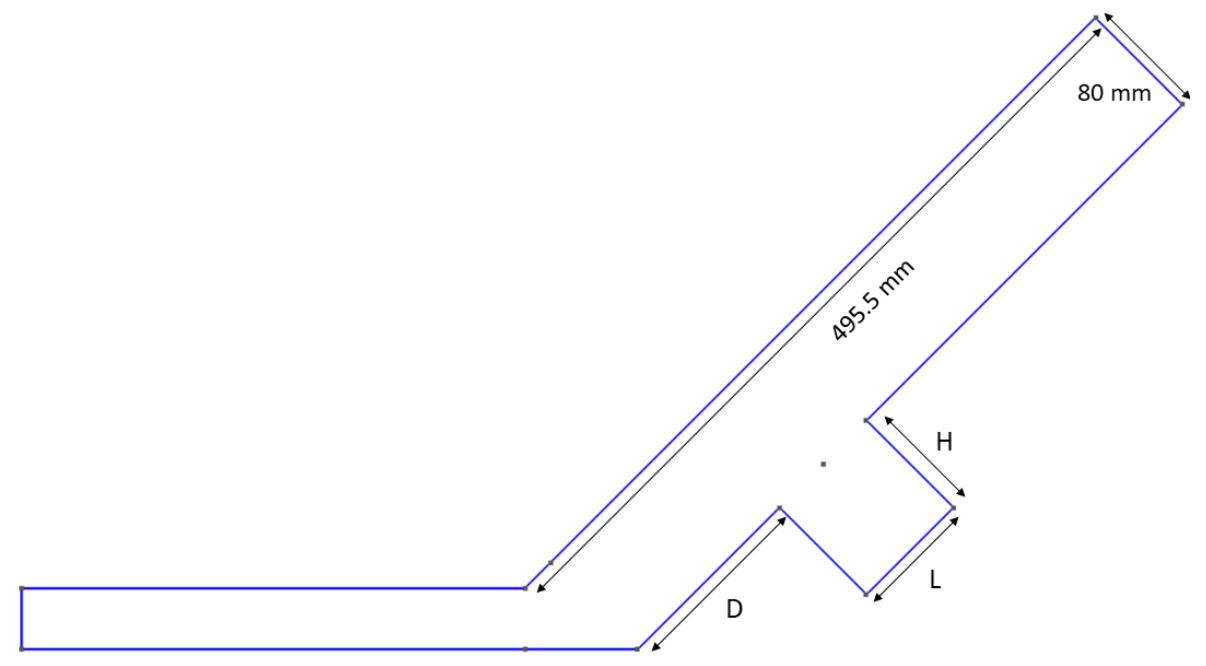

Fig.9 Geometric characteristics of the trap located on the lower wall.

Figure 10 represents the evolution of the reflected pressure ratio $\mathrm{P}_{r} / \mathrm{P}_{\max }$ for different value of $d$ and for the three shock wave Mach numbers.

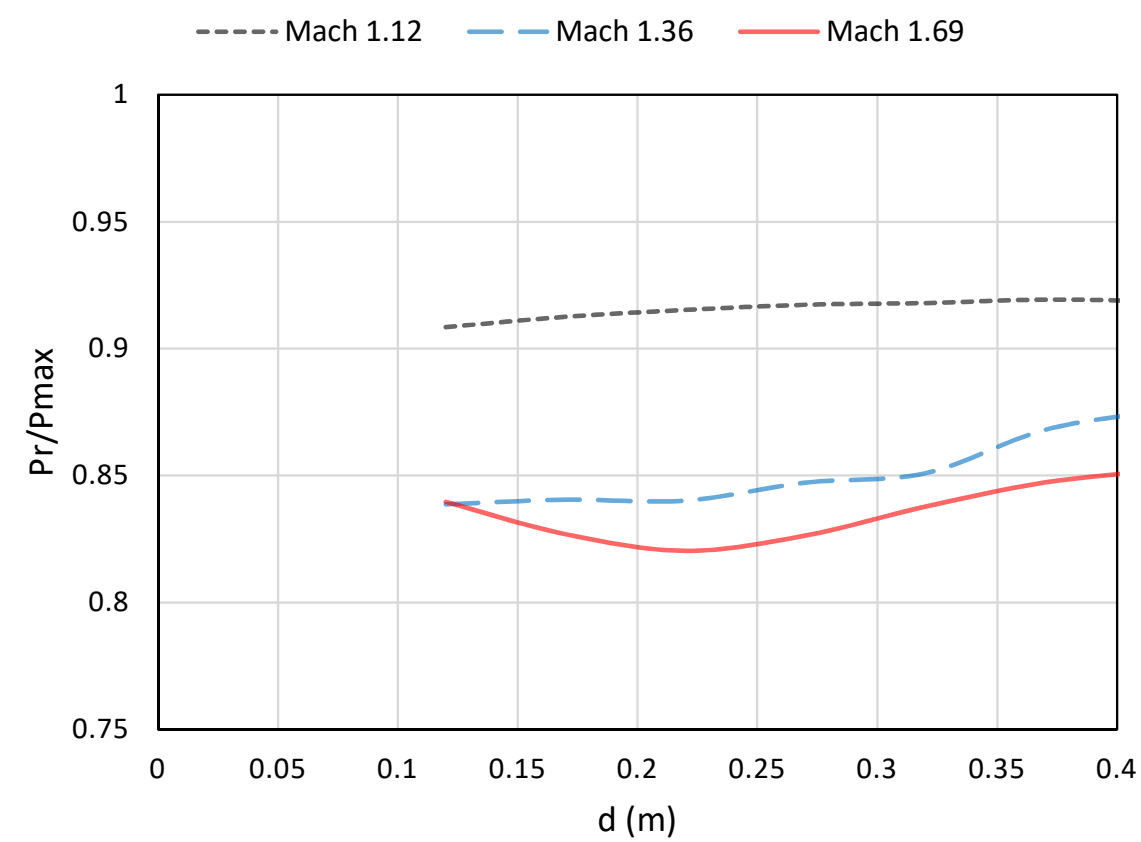

Fig.10 Evolution of the reflected pressure ratio $\mathrm{P}_{r} / \mathrm{P}_{\max }$ for different location of $\mathrm{d}$

Compared to the previous case where the trap was located on the upper branch, it is evident that in this configuration the location of the trap has less infuence on the mitigation 
of the reflected pressure. The presence of the trap is as important as the previous case on the ratio $\mathrm{P}_{r} / \mathrm{P}_{\max }$ (around $18 \%$ of mitigation), but its location on the lower wall is less important. However the maximum of mitigation is recorded for the stronger Mach number $(\mathrm{M}=1.69)$ corresponding to a value of $d$ equal to $0.22 \mathrm{~m}$. This value of $d$ is retained for the rest of the investigation about the size of the cavity.

\subsubsection{Influence of the parameter $L / H$}

Figure 11 presents the evolution of the reflected pressure ratio $\mathrm{P}_{r} / \mathrm{P}_{\max }$ for different values of $L / H$ for a trap located on the lower wall at the optimal value of $d=0.22 \mathrm{~mm}$. We can observe that the optimal ratio $L / H$ is between 1 and 4 .

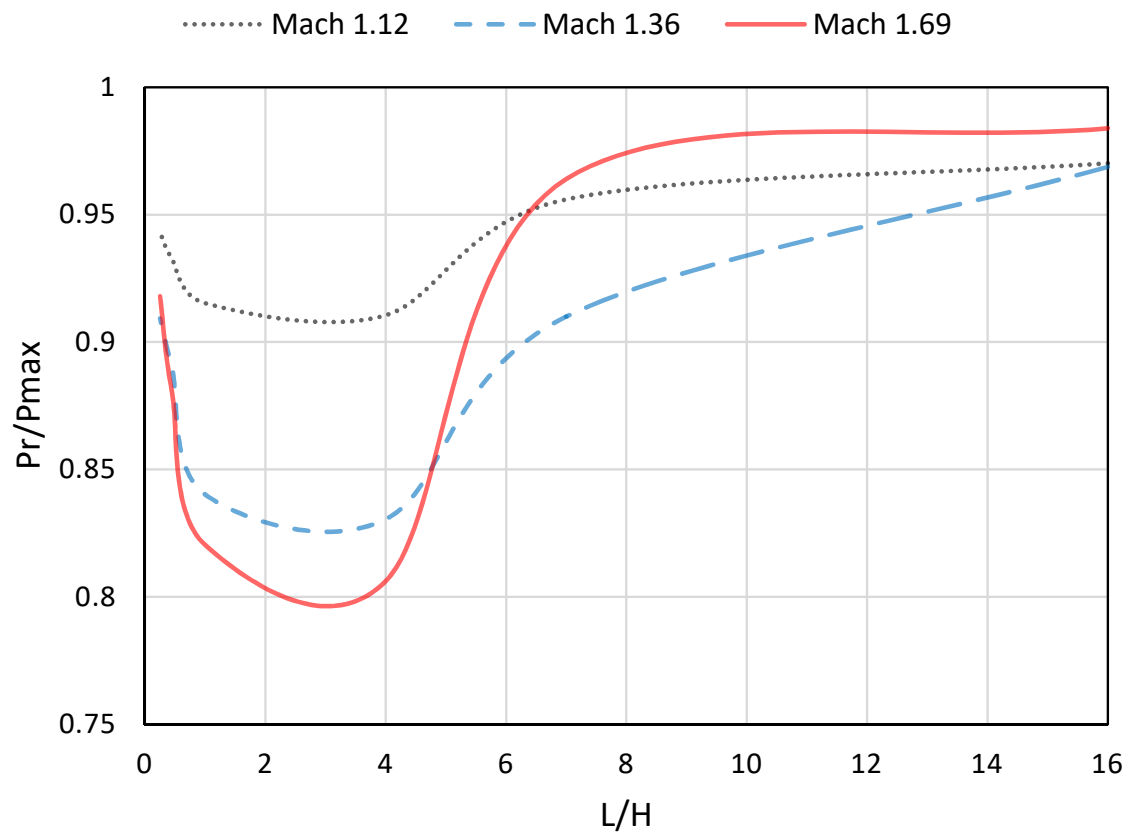

Fig.11 Evolution of the reflected pressure ratio $\mathrm{P}_{r} / \mathrm{P}_{\max }$ for different values of the parameter $L / H$

\subsection{Influence of a trap located at the point of bifurcation}

The study of the influence of a trap located at the point of bifurcation (see Fig.12) on the reflected pressure ratio $\mathrm{P}_{r} / \mathrm{P}_{\max }$ is summarized in the following section. 


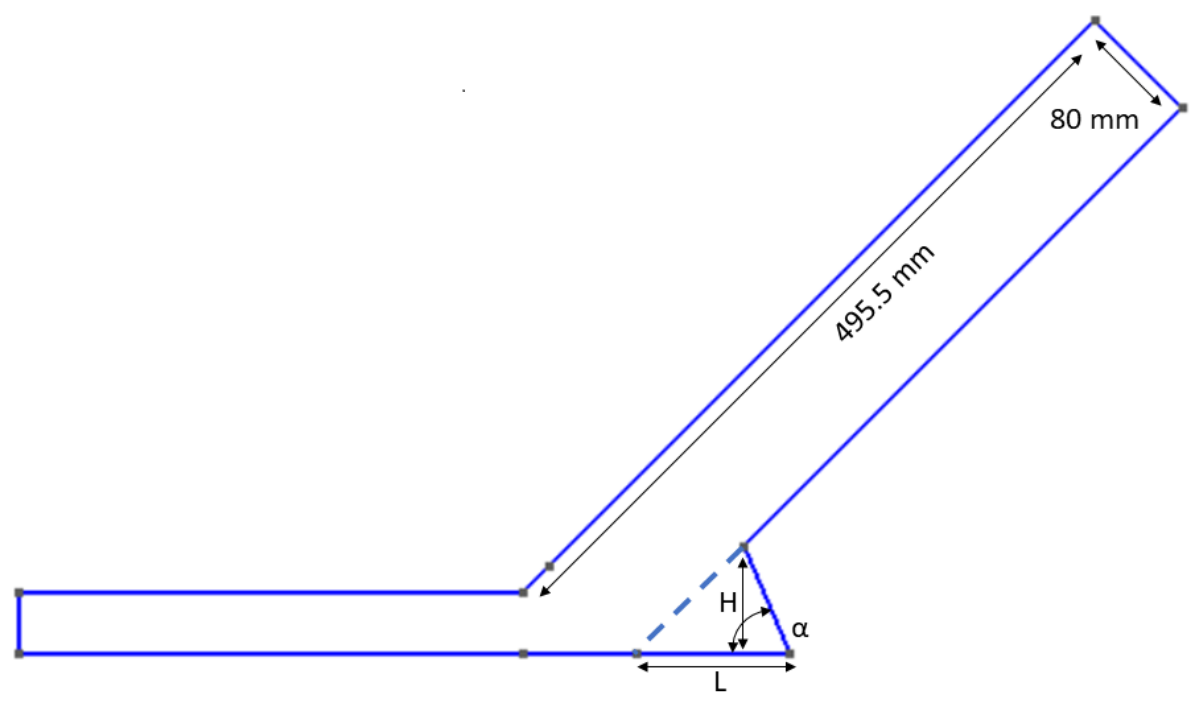

Fig.12 Geometric characteristics of the trap located at the point of bifurcation

Only the shape of the cavity is studied here and the angle $\alpha$ is between $\alpha=11.9^{\circ}$ and $\alpha=$ $89.54^{\circ}$. The details of the parameters are presented in Table 2. The different values of the parameters are choosen in order to keep the same cavity surface area which is arbitrarily set at $3500 \mathrm{~mm}^{2}$.

Table 2 Values of the parameters $L, H$ et $L / H(\mathrm{~m})$ and the corresponding angle $(\alpha$ in degrees)

\begin{tabular}{|c|c|c|c|}
\hline$L(\mathrm{~m})$ & $H(\mathrm{~m})$ & $R=L / H$ & $\alpha$ (degrees) \\
\hline 0.084 & 0.08333 & 1.008 & 89.54 \\
\hline 0.1 & 0.07 & 1.43 & 66.8 \\
\hline 0.125 & 0.056 & 2.23 & 39.06 \\
\hline 0.15 & 0.046667 & 3.21 & 24.3 \\
\hline 0.175 & 0.04 & 4.375 & 16.5 \\
\hline 0.2 & 0.035 & 5.7 & 11.9 \\
\hline
\end{tabular}

Figure 13 presents the evolution of the end-wall reflected pressure ratio $\mathrm{P}_{r} / \mathrm{P}_{\max }$ for different values of $\alpha$. It is clear that the ratio $L / H$ which affects both the depth and the height of the trap has a real influence on the mitigation of the end-wall reflected pressure. For the higher Mach number $(M=1.69)$ the mitigation reaches more than $20 \%$, for an angle between 24.3 and 66.8 degrees, compared to the case without the cavity. This makes this kind of trap the most effective between all the tested shapes. 


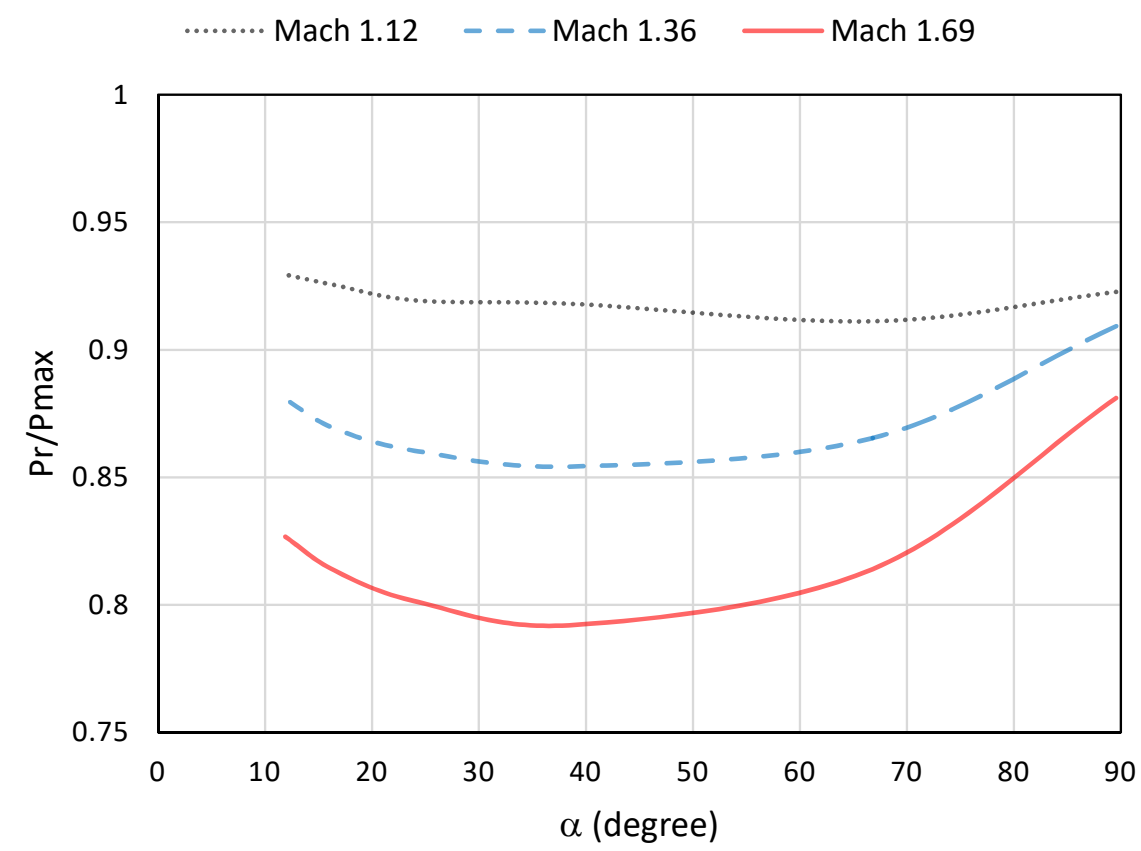

Fig.13 Evolution of the reflected pressure ratio $\mathrm{P}_{r} / \mathrm{P}_{\max }$ for different values of the angle $\alpha$ and three shock wave Mach numbers

\section{Conclusion}

This investigation explores the mitigation of the pressure level in the device with the addition of traps (cavities) along the studied configuration. A parametric study based on the shape and size of the cavities, shows that these parameters have a considerable influence on the pressure level in the duct system and can mitigate the end-wall reflected pressure up to $20 \%$ in the optimal case.

\section{Acknowledgements}

This work is supported by DGA/TN under contracts \#2015 15860056 and 201883 005601 and has received funding from Excellence Initiative of Aix-Marseille University (AMIDEX). It has been carried out in the framework of the Labex MEC.

\section{References}

[1] G. Ben-Dor, O. Igra, T. Elperin, Handbook of Shock Waves. (Academic Press, New York, 2000)

[2] O. Igra, X. Wu, J. Falcovitz, T. Meguro, K. Takayama, W. Heilig, Experimental and theoretical studies of shock wave propagation through double-bend ducts J. Fluid Mech. 437, 255-282 (2001)

[3] A. Marty, E. Daniel, J. Massoni, L. Houas, D. Leriche, G. Jourdan, Experimental and numerical investigations of shock wave propagation through a bifurcation, Shock Waves, 29, 2, pp 285296 (2018)

[4] K. Schmidmayer, A. Marty, F. Petitpas, E. Daniel, ECOGEN, an open-source tool dedicated to multiphase compressible multiphysics flows, 53rd 3AF International Conference on applied Aerodynamics, (2018). 